\section{Tumour-lysis-related elevation of intraocular pressure following high- dose-rate brachytherapy for choroidal melanoma}

AD Singh

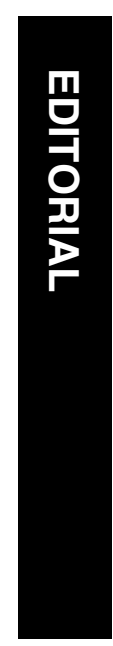

Eye (2004) 18, 793-794. doi:10.1038/sj.eye.6701335

About 5\% of all melanomas arise from the ocular and adnexal structures, and the majority $(85 \%)$ of ocular melanoma are uveal in origin. ${ }^{1}$ Uveal melanoma is the most frequent primary intraocular tumour in adults with an ageadjusted incidence of one per 4.3 per million in the United States. ${ }^{2}$ Enucleation has been the traditional method of treatment but at present there is a trend towards radiotherapy. ${ }^{3}$ Although various forms of radiotherapy, including helium ion radiotherapy, ${ }^{4}$ psroton beam radiotherapy, ${ }^{5}$ and stereotactic radiotherapy, ${ }^{6}$ have been advocated, brachytherapy using radioactive plaques is most widely used.? Following the pioneering works of Moore ${ }^{8}$ and Stallard 9 from the UK, advances in radiation physics have led to the development of lowenergy plaques such as ruthenium 106 plaque $^{10}$ which is predominantly used in Europe, and iodine 125 plaque $^{11}$ used in North America. Data derived from a large number of patients treated either with ruthenium $106^{12}$ or iodine 125 plaque $^{11}$ have shown that plaque radiotherapy is effective in controlling the primary tumour, preserving the globe in the majority of treated patients, and preserving useful vision in up to half of the treated patients. However, plaque radiotherapy does not offer any survival advantage over enucleation. ${ }^{13}$ The delivery of plaque radiotherapy involves close cooperation with the radiation oncologists and the radiation physicists who help to design, calibrate, plan, and monitor radiation therapy. The minimal tumour dose of $85 \mathrm{~Gy}$ at a dose rate of 0.60-1.05 $\mathrm{Gy} / \mathrm{h}$ for iodine 125 using AAPM TG-43
(American Association of Physics in Medicine Task Group 43$)^{14}$ formalism is recommended by the American Brachytherapy Society. ${ }^{15}$ The total delivered dose and the dose rate are important in achieving the desired biological effects. It has been shown that the risk of tumour recurrence increases if the dose rate is less than 0.50 $\mathrm{Gy} / \mathrm{h} .{ }^{16}$ On the other hand, risk of complications rises if the total delivered dose is higher than 160 Gy. ${ }^{16}$ Radiation complications following plaque radiotherapy are not limited to tumour recurrence or visual loss secondary to radiation retinopathy. Radiation-induced neovascular glaucoma is particularly bothersome and is one of the main reasons for enucleation following plaque radiotherapy, especially more than 3 years after radiotherapy. ${ }^{17}$ Multivariate analysis of the COMS data (Collaborative Ocular Melanoma Study) revealed that initial tumour height is the strongest predictor of enucleation following plaque radiotherapy, with a risk ratio of 2.4 (95\% CI, 1.3-4.2) for tumours more than $5.0 \mathrm{~mm}$ in height. ${ }^{17}$

In this issue, Kıratlı and Bilgiç ${ }^{18}$ report an unusual complication of secondary glaucoma due to pigment dispersion in eyes with uveal melanoma that were treated with Iodine 125 plaque radiotherapy. They attributed glaucoma to tumour lysis, solely based on clinical findings, as it was associated with pigment dispersion in the aqueous and vitreous and apparent blockage of the trabecular meshwork. The glaucoma occurred more than a year (mean period 17.4 months) following the plaque radiotherapy and could be controlled medically. In their series 36 of patients, seven (20\%) developed glaucoma. Eyes that developed tumour
Department of Ophthalmic Oncology, Cole Eye Institute Cleveland Clinic Foundation Cleveland, OH, USA

Correspondence: AD Singh Tel: + 12164459479

Fax: + 12164452226 E-mail: SINGHA@CCF.ORG 
lysis glaucoma had known risk factors for radiationrelated complications greater tumour height and higher dose rate. The mean preoperative tumour thickness in eyes with tumour lysis glaucoma was $10.1 \mathrm{~mm}$ as compared with $6.9 \mathrm{~mm}$ in eyes without glaucoma. Apical dose rates of the seven patients were significantly higher $(P=0.000)$ than the rest of the treated cases $(1.18-2.89$ and $0.64-1.09 \mathrm{~Gy} / \mathrm{h}$, respectively). Although the glaucoma could be controlled in the majority of eyes, the visual loss was significant due to coexisting radiation damage. Due to the small number of cases in the series, no adverse effect of tumour lysis on survival could be determined. The clinical distinction between pigment dispersion related to tumour lysis, ${ }^{19}$ from viable malignant cells indicative of tumour recurrence, can be challenging. ${ }^{19,20}$ In the absence of evidence of the detrimental effects of observation, perhaps careful follow-up with appropriate medical therapy in such cases is initially warranted.

\section{References}

1 Chang AE, Karnell LH, Menck HR. The National Cancer Data Base report on cutaneous and noncutaneous melanoma: a summary of 84,836 cases from the past decade. The American College of Surgeons Commission on Cancer and the American Cancer Society. Cancer 1998; 83: 1664-1678

2 Singh AD, Topham A. Incidence of uveal melanoma in the United States: 1973-1997. Ophthalmology 2003; 110: 956-961.

3 Singh AD, Topham A. Survival rate with uveal melanoma in the United States: 1973-1997. Ophthalmology 2003; 110: 962-965.

4 Char DH, Quivey JM, Castro JR, Kroll S, Phillips T. Helium ions versus iodine 125 brachytherapy in the management of uveal melanoma. A prospective, randomized, dynamically balanced trial. Ophthalmology 1993; 100: 1547-1554.

5 Gragoudas ES, Goitein M, Verhey L, Munzenreider J, Suit HD, Koehler A. Proton beam irradiation. An alternative to enucleation for intraocular melanomas. Ophthalmology 1980; 87: $571-581$.

6 Rennie I, Forster D, Kemeny A, Walton L, Kunkler I. The use of single fraction Leksell stereotactic radiosurgery in the treatment of uveal melanoma. Acta Ophthalmol Scand 1996; 74: 558-562.

7 Finger PT. Radiation therapy for choroidal melanoma. Surv Ophthalmol 1997; 42: 215-232.

8 Moore RF. Choroidal sarcoma treated by intraocular insertion of radon seeds. Br J Ophthalmol 1930; 14: 145-156.

9 Stallard HB. Radiotherapy for malignant melanoma of the choroid. Br J Ophthalmol 1966; 50: 147-155.

10 Lommatzsch PK. beta-Irradiation of choroidal melanoma with $106 \mathrm{Ru} / 106 \mathrm{Rh}$ applicators 16 Years' experience. Arch Ophthalmol 1983; 101: 713-717.

11 Earle J, Kline RW, Robertson DM. Selection of iodine 125 for the Collaborative Ocular Melanoma Study. Arch Ophthalmol 1987; 105: 763-764.

12 Seregard S. Long-term survival after ruthenium plaque radiotherapy for uveal melanoma. A meta-analysis of studies including 1,066 patients. Acta Ophthalmol Scand 1999; 77: 414-417.

13 Diener-West M, Earle JD, Fine SL, Hawkins BS, Moy CS, Reynolds SM et al. The COMS randomized trial of iodine 125 brachytherapy for choroidal melanoma, III: initial mortality findings. COMS Report No. 18. Arch Ophthalmol 2001; 119: 969-982.

14 Nath R, Anderson LL, Luxton G, Weaver KA, Williamson JF, Meigooni AS. Dosimetry of interstitial brachytherapy sources: recommendations of the AAPM Radiation Therapy Committee Task Group No. 43 American Association of Physicists in Medicine. Med Phys 1995; 22: 209-234.

15 Nag S, Quivey JM, Earle JD. The American Brachytherapy Society recommendations for brachytherapy of uveal melanomas. Int J Radiation Oncology Biol Phys 2003; 56: 544-555.

16 Quivey JM, Augsburger J, Snelling L, Brady LW. 125I plaque therapy for uveal melanoma. Analysis of the impact of time and dose factors on local control. Cancer 1996; 77: 2356-2362.

17 Jampol LM, Moy CS, Murray TG. The COMS randomized trial of Iodine 125 brachytherapy for choroidal melanoma. Ophthalmology 2002; 109: 2197-2206.

18 Kıratlı H, Bilgiç S. Tumour-lysis related elevation of intraocular pressure following high-dose rate brachytherapy for choroidal melanoma. Eye 2004; 18: 799-803.

19 Robertson DM. Choroidal melanomas with a collar-button configuration: response pattern after iodine- 125 brachytherapy. Arch Ophthalmol 1999; 117: 771-775.

20 Robertson DM, Campbell RJ. Intravitreal invasion of malignant cells from choroidal melanoma after brachytherapy. Arch Ophthalmol 1997; 115: 793-795. 